\section{7-Nitroindazole down-regulates dopamine/DARPP-32 signaling in neostriatal neurons in a rat model of Parkinson's disease}

Q4 J.E. Yuste, M.B. Echeverry, F. Ros-Bernal, A. Gomez, C.M. Ros, C.M. Campuzano, E. Fernandez-Villalba, M.T. Herrero*

Q1 Clinical E Experimental Neuroscience (NICE) and Centro de Investigación Biomédica en Red sobre Enfermedades Neurodegenerativas (CIBERNED), Department of Human Anatomy and Psychobiology, School of Medicine, University of Murcia, Campus de Espinardo, 30100 Murcia, Spain

\section{A R T I C L E I N F O}

Article history:

Received 2 November 2011

Received in revised form

8 July 2012

Accepted 15 July 2012

\section{Keywords:}

6-OHDA

Dorsolateral

Neostriatum

$\mathrm{SNpc}$

$\mathrm{TH}$

nNOS

DARPP-32

7-NI

EBST

\begin{abstract}
A B S T R A C T
Neuronal nitric oxide synthase (nNOS) is involved in the regulation of diverse intracellular messenger systems in the brain. Nitric Oxide (NO) contributes to inducing signaling cascades that involve a complex pattern of phosphorylation of DARPP-32 (in Thr-34), which controls the phosphoproteins involved in neuronal activation. However, the role of NO in the pathophysiology of Parkinson's disease (PD) and its effect in striatal neurons have been scarcely explored. In the present work, we investigate the effects of a nitric oxide synthase (NOS) inhibitor, 7-nitroindazole (7-NI) in the nigrostriatal pathway of striatal 6hydroxydopamine (6-OHDA) lesioned rats. Our quantitative histological findings show that treatment with 7-NI significantly reduced 6-OHDA-induced dopaminergic damage in the dorsolateral striatum and Substantia Nigra pars compacta (SNpc). Moreover, 6-OHDA lesioned rats show a significant increase of nNOS $^{+}$and Phospho-Thr34-DARPP- $32^{+}$cells, accompanied by a consequent decrease of total DARPP-32 cells, which suggests an imbalance of NO activity in the DA-depleted striatum, which is also reflected in behavioral studies. Importantly, these effects are reverted in the group treated with 7-NI. These results show a clear link between the state of phosphorylation of DARPP-32 and parkinsonism, which is regulated by nNOS. This new evidence suggests a prominent role for nitric oxide in the neurotransmitter balance within the basal ganglia in the pathophysiology of experimental parkinsonism.
\end{abstract}

(ㄷ) 2012 Published by Elsevier Ltd.

\section{Introduction}

Idiopathic Parkinson's disease (PD) is a common age-related resting tremor and postural instability. The neuropathological hallmarks of PD are the progressive loss of dopaminergic neurons in the Substantia Nigra pars compacta $(\mathrm{SNpc})$ and the presence of Nitroindazole; DA, dopamine; NO, Nitric Oxide; 6-OHDA, 6-Hydroxydopamine; $\mathrm{TH}$, Tyrosin Hydroxylase; $\mathrm{CPu}$, Caudate-Putamen complex; SNpc, Substantia Nigra pars compacta; cNOS, calcium-dependent NOS; nNOS, neuronal Nitric Oxide synthase; eNOS, endothelial Nitric Oxide Synthase; NA, noradrenergic; PhosphoThr34-DARPP-32, $32 \mathrm{kDa}$ dopamine and cyclic AMP-regulated phosphoprotein in Thr-34; Total DARPP-32, $32 \mathrm{kDa}$ dopamine and cyclic AMP-regulated total protein; EBST, Elevated Body Swing Test; cGMP, cyclic guanosine monophosphate; SDS, sodium dodecylsulfate; DAT, dopamine transporter; MAO-B, Monoamine oxidase B; sGC, soluble guanylyl cyclases; PP-1, Protein phosphatase-1; PKG, Protein kinase G; PKA, Protein Kinase A; MSN, Medium spiny neuron; LTD, long-term depression; LTP, long-term potentiation.

* Corresponding author. Tel: +34 8688846 83; fax: +34 868884150 .

E-mail address: mtherrer@um.es (M.T. Herrero). movement disorder characterized by bradykinesia, rigidity,

Abbreviations: PD, Parkinson's disease; NOS, nitric oxide synthase; 7-NI, 7- intraneuronal cytoplasmic inclusions (Lewy bodies) in some surviving nigral dopaminergic (DA) neurons. The clinical manifestation of PD occurs when about $50 \%$ of nigral dopaminergic neurons and about $70 \%$ of striatal dopamine fibres are lost (Hornykiewicz and Kish, 1987; Von Bohlen Und Halbach, 2004). This loss of DA fibers in the striatum causes disorganization of the activity of the striatal neurons, accompanied by a subsequent alteration of the basal ganglia circuitry with detrimental effects for the patients concerned.

Nitric oxide (NO) has emerged as a key endogenous modulator of $\mathbf{0 2}$ the neuronal function, but its role in the regulation of the activity of striatal neurons and its implication for PD are still unclear. NO is an intracellular and short-lasting molecule that is synthesized from Larginine in several brain regions by a reaction catalyzed by NO synthase (NOS) (Ignarro, 1990; Dawson et al., 1991). NOS is located in neurons, perivascular nerves, glial cells and the endothelium (Bredt and Snyder, 1990; Murphy et al., 1993). The family of NOS, the enzymes that induce NO, consists of two different classes: the inducible and constitutive forms (Dawson and Snyder, 1994; Marletta, 1994). Additionally, among the constitutive forms, there are two calcium-dependent NOS (cNOS) isoforms: the neuronal NOS 
(nNOS) present in neurons, and the endothelial NOS (eNOS) present in both pyramidal cells and endothelial cells (Moncada et al., 1991).

Even if both NOS positive cell type have been found in basal ganglia (Vincent and Kimura, 1992), the function of nNOS in basal ganglia circuitry remains scarcely explored. In ex vivo striatal slices, it has been demonstrated that postsynaptic effects of DA are conferred to a $32 \mathrm{kDa}$ dopamine- and cyclic AMP-regulated phosphoprotein (DARPP-32) (Nishi et al., 2005) in striatal projection neurons, which receive the bulk of DA innervation within the basal ganglia. Through interactions with multiple kinases and phosphatases, DARPP-32 regulates the phosphorylation levels, and thereby the activity of a broad range of target proteins (Greengard et al., 1999). In addition to DA, numerous neurotransmitters, peptides and neuromodulators have been shown to provide input to DARPP32-associated signal transduction cascades (Greengard et al., 1999). This evidence highlights the importance of DARPP-32 as a critical component of signal integration in striatal projection neurons. Several recent studies have emphasized a crucial role for the nitrergic system in movement control and the pathophysiology of the basal ganglia (Pierucci et al., 2011). The NO produced is diffused into medium spiny neurons of the striatum, resulting in the formation of cGMP and activation of protein kinase $G$ (PKG), where the DARPP-32, an excellent substrate for PKG and protein kinase A (PKA), is phosphorylated (Tsou et al., 1993; Nishi et al., 2005). These studies also suggest that the effects of nitric oxide on striatal neurons are partially mediated via cyclic guanosine monophosphate (cGMP) (West and Tseng, 2011).

However, the role of nNOS in the striatum pathway in parkinsonism in vivo is unknown and there are few studies concerning the influence of nNOS inhibition on the DA loss in vivo (Hantraye et al., 1996; Ferrante et al., 1999).

In the present work, we used a specific inhibitor of nNOS, 7nitroindazole (7-NI) (Southan and Szabó, 1996), a relatively selective inhibitor of the neuronal isoform of nitric oxide synthase, in a model of PD induced by the intrastriatal injection of 6-OHDA (Di Matteo et al., 2009), observing that inhibition of nNOS has an important effect on the regulation of DARPP-32 signaling in the striatum of hemiparkinsonian rats. This suggests a prominent role for nNOS in the regulation of the activity of striatal neurons in parkinsonism.

\section{Experimental procedures}

\subsection{Animals}

Sixty-four adult male Sprague-Dawley rats weighing 250-300 g (purchased from Harlan) were housed in groups of four animals per cage in a temperature-controlled room $\left(21 \pm 1{ }^{\circ} \mathrm{C}\right)$, under a 12-h light-dark cycle, with free access to food and water. All animals experiments were carried out in accordance with the U.K. Animals (Scientific procedures) Act, 1986, and associated guidelines, and the European Communities Council Directive of 24 November 1986 (86/609/ECC) for the care and use of laboratory animals. All efforts were made to minimize animal suffering and to reduce the number of animals used in these experiments.

\subsection{Surgical procedures: 6-OHDA microinjections}

The rats were anesthetized with a mixture of ketamine/xylazine (50 mg/kg; $10 \mathrm{mg} / \mathrm{kg}$ i.p.) and placed on a stereotaxic frame (Kopf Texas Instruments). Unilateral striatal lesions were performed by microinjecting 6-OHDA with $0.02 \%$ ascorbic acid $(4 \mu \mathrm{g} / \mu \mathrm{l}$, RBISigma) in $0.9 \%$ saline into the right striatum ( 2 microinjections of $2 \mu \mathrm{l}$ each) with a $10 \mu \mathrm{l}$ Hamilton syringe, at a rate of $1 \mu \mathrm{l} / \mathrm{min}$. The concentration of 6-OHDA was selected on the basis of its successful use for inducing lesions restricted to the dorsolateral striatum in the rat, which rotated, in response to treatment with apomorphine (Schwarting and Huston, 1996). To prevent noradrenergic (NA) failure, 10 min before the 6-OHDA injection, the animals were treated with desmethylimipramine (inhibitor of the high affinity noradrenaline transport system, $25 \mathrm{mg} / \mathrm{kg}$ i.p., Sigma) and pargyline (inhibitor of the monoamino-oxidase enzyme, $40 \mathrm{mg} / \mathrm{kg}$ i.p., Sigma). The stereotaxic coordinates of the two injections, according to Paxinos \& Watson's rat brain Atlas (1998), locating the tooth bar at $-2.4 \mathrm{~mm}$, were: (First injection) anterior: $1.20 \mathrm{~mm}$; lateral: $2.5 \mathrm{~mm}$; ventral: $-4.5 \mathrm{~mm}$; and (second injection) anterior: $0.48 \mathrm{~mm}$; lateral: $3.4 \mathrm{~mm}$; ventral: $-5.0 \mathrm{~mm}$ from bregma. Shamoperated control animals $(n=9)$ were injected with saline (vehicle) instead of the neurotoxin using the same procedure. After the injection, the syringe was left in the target for an additional 2 min before removal.

\subsection{Pharmacological treatment}

The 7-NI (purchased from RBI-Sigma) administrations started 30 min before the stereotaxic surgery. The inhibitor was dissolved in peanut oil and administered for 5 days (one per day) at a therapeutic dose, previously tested in preliminary experiments, thus preventing cataleptic behavior in the animals $(15 \mathrm{mg} / \mathrm{kg}$, i.p., $\times 5)$ (Guevara et al., 2002; Padovan-Neto et al., 2009). Every group, Sham or lesioned, was divided into two subgroups, treated with vehicle (peanut oil) or treated with 7-NI: i) Sham + vehicle $(n=9)$, ii) Sham $+7-\mathrm{NI}(n=9)$, iii) $6-\mathrm{OHDA}+$ vehicle $(n=11)$ and iv) $6-\mathrm{OHDA}+7-\mathrm{NI}(n=11)$.

The rats were placed in clean cages on warming pads bedding to recover from the surgery, after which they were returned the group housing (two or three rats per cage).

\subsection{Behavioural tests}

\subsubsection{Evaluation of rotational behavior}

To determine the success of unilateral striatal denervation, rats were injected with apomorphine hydrochloride $(0.5 \mathrm{mg} / \mathrm{kg}$ s.c., RBI-Sigma) 15 days after the 6-OHDA lesions. The total number of (contralateral) rotations was recorded every $5 \mathrm{~min}$ for $45 \mathrm{~min}$ (Padovan-Neto et al., 2009). Turns were counted by a rotometer (Ungerstedt and Arbuthnott, 1970) [built in the CAID (Centro de Apoyo a la Investigación y al Desarrollo) of our university]. The behavioral evaluation was performed blindly by the observers. Given that after 6-OHDA lesion small depletions of striatal DA were associated with a lower intensity of rotations with apomorphine (Costall et al., 1976), only animals in the 6-OHDA/Veh group, which exhibited more than 15 total turns contralateral to the side of the 6OHDA lesion, in $45 \mathrm{~min}$, were included in this study.

\subsubsection{Elevated body swing test (EBST)}

An additional evaluation with EBST was made to verify the partial striatal lesion (Blandini et al., 2007) and to avoid the behavioral sensitization effects of repeated apomorphine injections. The EBST was performed to evaluate 6-OHDA-treated animals 35 days after the lesion as previously described (Borlongan and Sanberg, 1995). The animals were placed in a Plexiglas box $(40 \times 40 \times 35.5 \mathrm{~cm})$ for $2 \mathrm{~min}$ for habituation. Then, each rat was held $3 \mathrm{~cm}$ from the base of its tail and suspended approximately $3 \mathrm{~cm}$ above the table. In this position the animals start swinging to the right or left side and the events counted. The animal must return to the outstretched position for the next swing to be counted. At the beginning, a gentle pinch in the tail may stimulate the behavior. The number of left-biased (L) swings and right-biased $(\mathrm{R})$ swings were counted during a period of $1 \mathrm{~min}$. Biased swinging 
behavior was calculated as follows: L (\% of total BS for left-biased swings) and $\mathrm{R}$ (\% of total BS for right-biased swings), Total $\mathrm{BS}=\mathrm{L}+\mathrm{R}$. All experimental tests were performed at the same time of day (Fig. 1, panel A.2).

\subsubsection{Tissue preparation}

To study the histological effects of the lesion, forty days after the last behavioral screening, 40 animals were deeply anesthetized with a mixture of ketamine/xylazine (50 mg/kg; $10 \mathrm{mg} / \mathrm{kg}$ i.p.) and transcardially perfused with PBS $0.01 \mathrm{M}(300 \mathrm{ml}$; pH 7.4) followed by $4 \%$ paraformaldehyde in $0.1 \mathrm{M}$ phosphate buffer $(250 \mathrm{ml}$; $\mathrm{pH}$ 7.4). The brains were rapidly removed and postfixed in the same fixative solution for $24 \mathrm{~h}\left(4{ }^{\circ} \mathrm{C}\right)$ and then cryoprotected in 30\% sucrose/phosphate buffer. Brains were quickly frozen in cold isopentane $\left(-40{ }^{\circ} \mathrm{C}\right.$; Sigma $)$ and stored at $-80{ }^{\circ} \mathrm{C}$ until the histochemical and immunocytochemical procedures were carried out.

\subsubsection{Immunohistochemistry and histochemistry}

Thirty $\mu \mathrm{m}$-thick serial coronal sections were cut in a cryostat (Leica). After a period of time, adjacent brain sections containing Caudate-Putamen complex $(\mathrm{CPu})$ nucleus or SNpc were immunostained for TH, DARPP-32 and nNOS. TH immunohistochemistry was performed as previously described (Barcia et al., 2004), and the same procedure was carried out for nNOS, total DARPP-32 and the same protein, phosphorylated at Thr-34. Briefly, tissue sections were washed and then incubated for $18-24 \mathrm{~h}$ with the primary antibody (TH, 1:1000, Calbiochem; NOS1, 1:1000, Santa Cruz; total DARPP-32 and DARPP-32 phospho T34, 1:400, Abcam ab51139 and ab51076, respectively). Sections were processed by the avidinbiotin immunoperoxidase method (Vectastain ABC kit, Vector Lab) and immunopositive cells were visualized by addition of the chromogen 3,3'-diaminobenzidine (DAB; Sigma, $1 \mathrm{mg} / \mathrm{ml}$ ) and hydrogen peroxide $(0.2 \%)$. For both DARPP-32, $1 \%$ Nickel was added to visualize the cells with greater contrast. Sections were mounted on gelatin-coated glass slides, dehydrated in ethanol, cleared in xylene and cover-slipped for microscopic observations. Cytoplasmic DARPP-32 positive cells could be visualized as a blue or dark blue reaction product, respectively, and nNOS and TH as a brown precipitate. In all experiments, tissues from Sham and all lesioned groups were always processed in the same assay.

\subsubsection{Western blotting analysis}

Ten Sham rats groups and fourteen 6-OHDA rats groups were killed by decapitation $30 \mathrm{~min}$ after the last 7-NI injection. The
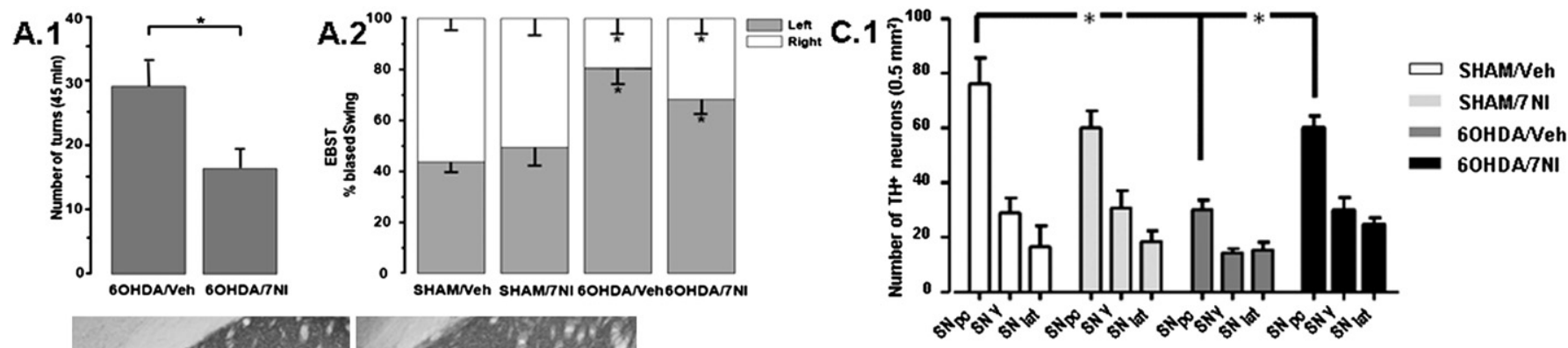

B.1
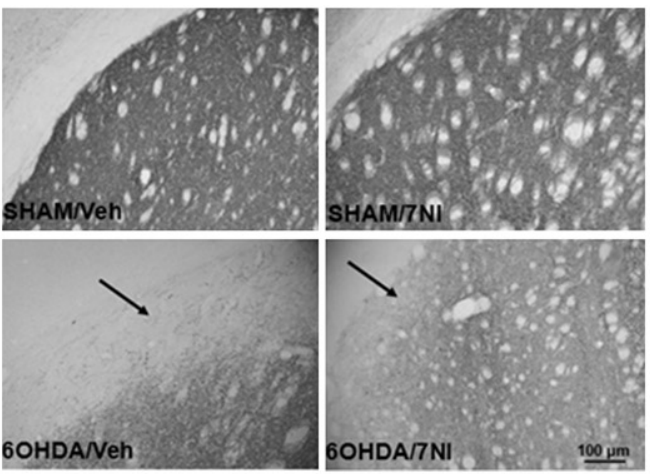

B.2
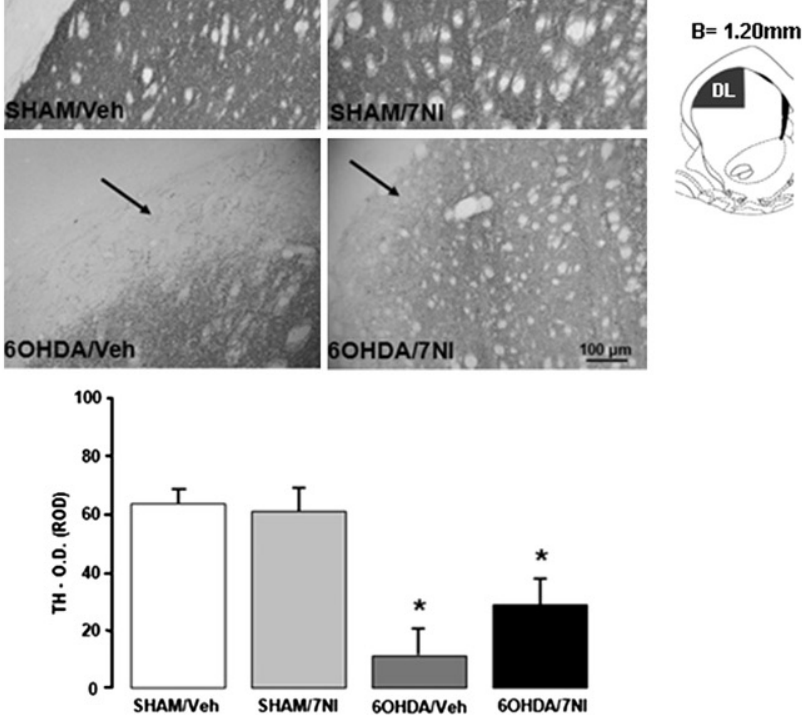

C.2
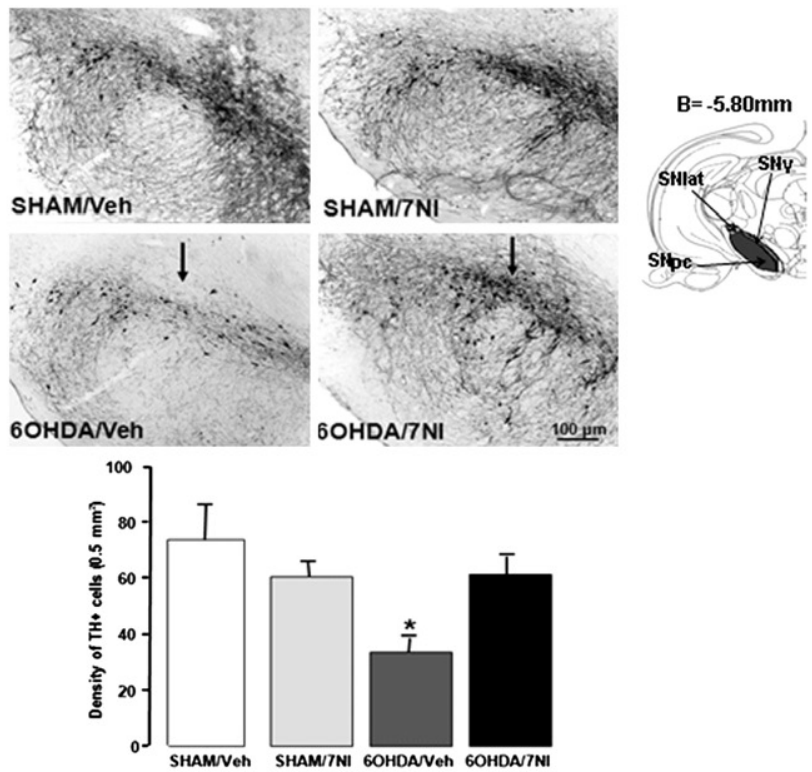

Fig. 1. Striatal injections of 6-OHDA causes a mild parkinsonism in rats which is reverted by 7-NI treatment. (A.1) The number of apomorphine-induced turns, 15 days after lesion, were significantly lower in the 6-OHDA/7-NI group than in the 6-OHDA/Veh group. (A.2) The left-biased swings measured by EBST 35 days after lesion in the 6-OHDA/Veh group were increased by $70 \%$ compared with Sham animals. ${ }^{*} \mathrm{P}<0.05$ lesioned animals vs Sham groups (ANOVA followed by the Duncan test). Photomicrographs show the distribution of $\mathrm{TH}^{+}$fibers in the dorsolateral striatum (B.1) and $\mathrm{TH}^{+}$neurons in the SNpc (C.2) in the different experimental groups, 45 days post-lesion. Schematics illustrations of the analyzed coronal section are shown on the right. Each bar of the histograms corresponds to mean \pm SEM. The treatment with 7-NI moderately attenuated the loss of $\mathrm{TH}^{+}$fibers $(\mathrm{B} .2)$ and protected the cells (C.2) in both structures, respectively (striatum and $\mathrm{SNpc}$ ), in 6-OHDA-lesioned animals. $\mathrm{TH}^{+}$neurons in the ventral mesencephalon in a section containing the intra-axial portion of the third craneal-nerve. The three different regions, analyzed of the SN are indicated in the scheme on the right to panel (C.2). In panel (C.1) a graph showing the count of $\mathrm{TH}+$ neurons in the 3 areas of the $\mathrm{SN}\left(\mathrm{SNpc}, \mathrm{SN} \gamma\right.$ and $\mathrm{SN}_{\text {lat }}$ ). The AP localization of the analyzed Substantia Nigra area was AP $-5.80 \mathrm{~mm}$ from bregma. We found only a significant difference in the SNpc with respect to other areas (ANOVA, $F_{(3,15)}=3.24$, post-hoc Newman-Keuls). ${ }^{*} P<0.05,6-O H D A / V e h ~ v s$ Sham/Veh and 6-OHDA/7-NI. OD: Optical Density, ROD units: Relative Optical Density units. 
brains were removed, and the striata dissected out on an ice-cold surface. The structure was immediately immersed in liquid nitrogen. Samples were placed in homogenization buffer [phosphate buffered saline, $2 \%$ sodium dodecylsulfate (SDS) plus protease inhibitors (Roche, Germany) and phosphatase inhibitors Cocktail Set (Calbiochem, Germany)] and homogenized for $50 \mathrm{~s}$ prior to centrifugation at $6000 \mathrm{~g}$ for $20 \mathrm{~min}$ at $4{ }^{\circ} \mathrm{C}$. Total protein concentrations were determined spectrophotometrically using the bicinchoninic acid method (Wiechelman et al., 1988). The optimum amount of protein to be loaded was determined in preliminary experiments by loading gels with increasing protein contents $(25-100 \mu \mathrm{g})$ from samples of each experimental group. Equal amounts of protein $(50 \mu \mathrm{g} / \mathrm{lane})$ from each sample were loaded on a $10 \%$ SDS-polyacrylamide gel (SDS-PAGE), electrophoresed, and transferred onto a poly vinylidene difluoride (PVDF) membrane using a Mini Trans-Blot Electrophoresis Transfer Cell (Bio-Rad Lab., California, USA). Non-specific binding of antibodies was mitigated by incubating membranes with $1 \%$ bovine serum albumin (BSA) in tris buffer saline tween (TBST: $10 \mathrm{mM}$ Tris- $\mathrm{HCl}, \mathrm{pH}$ 7.6, $150 \mathrm{mM}$ $\mathrm{NaCl}$, and $0.05 \%$ Tween 20). Membranes were immunoblotted overnight using selective antibodies against Phospho-Thr34DARPP-32 (1:1000; Cell Signaling Technology) and Total DARPP32 (1:1000; Cell Signaling Technology). After extensive washings with TBST, the membranes were incubated for $1 \mathrm{~h}$, at room temperature, with peroxidase-labeled secondary antibodies (antirabbit sc-2004 for DARPP-32 phosphorylated at Thr-34 and Total DARPP-32, at 1:2000 dilutions). After washing, immunoreactivity was detected with an enhanced chemiluminescent/chemifluorescent western blot detection system (ECL Plus, GE Healthcare, U.K) and visualized by a Typhoon 9410 variable mode Imager (GE Healthcare). Antibodies were stripped from the blots by incubation with stripping buffer (glycine $25 \mathrm{mM}$ and SDS $1 \%, \mathrm{pH}=2$ ), for $1 \mathrm{~h}$ at $37{ }^{\circ} \mathrm{C}$. Anti $\beta$-actin was used as housekeeper (Cell Signaling, $45 \mathrm{kDa}$ ). The ratio of total DARPP-32/ $\beta$-actin, phospho-DARPP-32/ $\beta$ actin was plotted and analyzed.

\subsection{Quantitative methods}

\subsubsection{Immunohistochemistry and histochemistry}

The whole histological quantification was performed blindly. Neuroanatomical sites (Dorsolateral striatum and SNpc) were identified using the Paxinos and Watson (1998) atlas. The anteroposterior (AP) localization of the analyzed dorsolateral striatum area was AP $1.20 \mathrm{~mm}$ from bregma (Fig. 1, panel B.1). Stained neurons were counted using a computerized image analysis system. Images were captured from slices using a computerassisted image analysis system (Image 1.43 Analysis software from directory at rsb.info.nih.gov/ij/ with a Zeiss microscope connected to a digital camera (CoolSnap) through a Zeiss zoom set at $10 \times$ and a $0.1 \times$ adapter (Barcia et al., 2004)). The loss of dopaminergic fibers in the dorsolateral striatum was analyzed by measuring the optical density of the $\mathrm{TH}$ immunoreactivity with a computer analyzer (ImageJ System).

The optical density of a tissue area devoid of staining (corpus callosum) was measured, adjusting the light intensity to give a background density value. The background was subtracted from all subsequent measurements. A mean value for staining intensity was calculated and expressed on an arbitrary gray scale (relative optical density) units (ROD units; Echeverry et al., 2004). The boundary of SNpc was outlined under magnification of the $4 \times$ objective. Cells were counted with a $40 \times$ oil-immersion objective using a Nikon $80 \mathrm{i}$ microscope. Serial sections through the whole SNpc were placed 6 per slide (cut thickness of $30 \mu \mathrm{m}$ ) for systematic analysis of randomly placed counting frames (size $50 \times 50 \mu \mathrm{m}$ ) on a counting grid (size of $190 \times 130 \mu \mathrm{m}$ ) and sampled using an $18 \mu \mathrm{m}$ optical dissector with $2 \mu \mathrm{m}$ upper and lower guard zones. The nNOS labeled neurons were quantified in the dorsolateral region of the striatum (Fig. 2). For quantification of labeled neurons and cytoplasmic DARPP-32, an average number from a fixed size/area of the dorsolateral part of caudate nucleus was observed (Figs. 3-4). For each treatment, three sections from each animal were evaluated. A mean value for the number of cells in the three regions of the animal was then calculated.

\subsubsection{Western blot analysis}

All the quantifications for the immunoblot analysis corresponding to total DARPP-32 (32 kDa) and DARPP-32 phosphorylated at Thr-34 (32 kDa) bands were carried out by densitometry (AlphaImager, Nucliber, Madrid). We measured the integrated optical density of bands. The software generates quantitative data of band intensities. The values are in units of pixel gray levels and are proportional to the light intensity on that pixel during the exposure time of the image. The optical density was normalized to the background values. Relative variations between bands of experimental samples and control samples were calculated in the same image.

\subsection{Statistical analysis}

All values were expressed as mean \pm S.E.M. Analysis of variance (ANOVA) for repeated measures was performed, taking as intrasubject factor the side of the brain, and the treatment as the factor between groups to analysis interaction between factors. In case of effect on treatment factor, differences between groups were analyzed using one-way ANOVA. The Duncan test was used for multiple comparison procedures. Differences between means were analyzed using one-way ANOVA. The Duncan test was used for multiple comparison procedures. Pearson $r$ correlation was used to assess any correlation between the densitometry of $\mathrm{TH} v s$ rotational behavior, as well as between phospho-Thr34-DARPP-32 vs nNOS, TH vs nNOS and total DARPP-32 vs phospho-Thr34-DARPP-32. For Western blot analysis we used one-way ANOVA followed by the Newman-Keuls post-hoc test. A significance level of $P<0.05$ was considered to be statistically significant.

\section{Results}

In the left side (contralateral to lesion) in dorsolateral striatum there was not any alteration by the lesion. (see Table 1 ).

\subsection{7-NI reverts parkinsonian behavior in 6-OHDA-lesioned rats}

The treatment with apomorphine induced contralateral rotations in 6-OHDA-lesioned animals but not in control animals. However, a significant decrease in the number of rotations was seen in 7-NI compared to vehicle treated rats (control animals did not show any rotations (Sham/Vehicle, $n=4$; Sham/7-NI, $n=5$ ) (ANOVA, $F_{(3,19)}=20.70, P<0.001$ ) (Fig. 1, panel A.1)).

Although stereotyped behavior may be observed as a typical response to the lesion in the striatum of the rat (Iversen and Koob, 1977; Old et al., 1999), in our animals no significant differences were observed between the experimental groups. The percentage of left-biased swings measured by EBST five weeks after the striatal-lesion was significantly higher than in Sham rats (Duncan, $P<0.05$ ). 6-OHDA/Vehicle animals showed more than a $70 \%$ increase in the number of left-biased swings compared with Sham animals. A decrease not significant, was observed in 6-OHDA/7-NI animals (Duncan, $P>0.05$ ) (Fig. 1, panel A.2). 

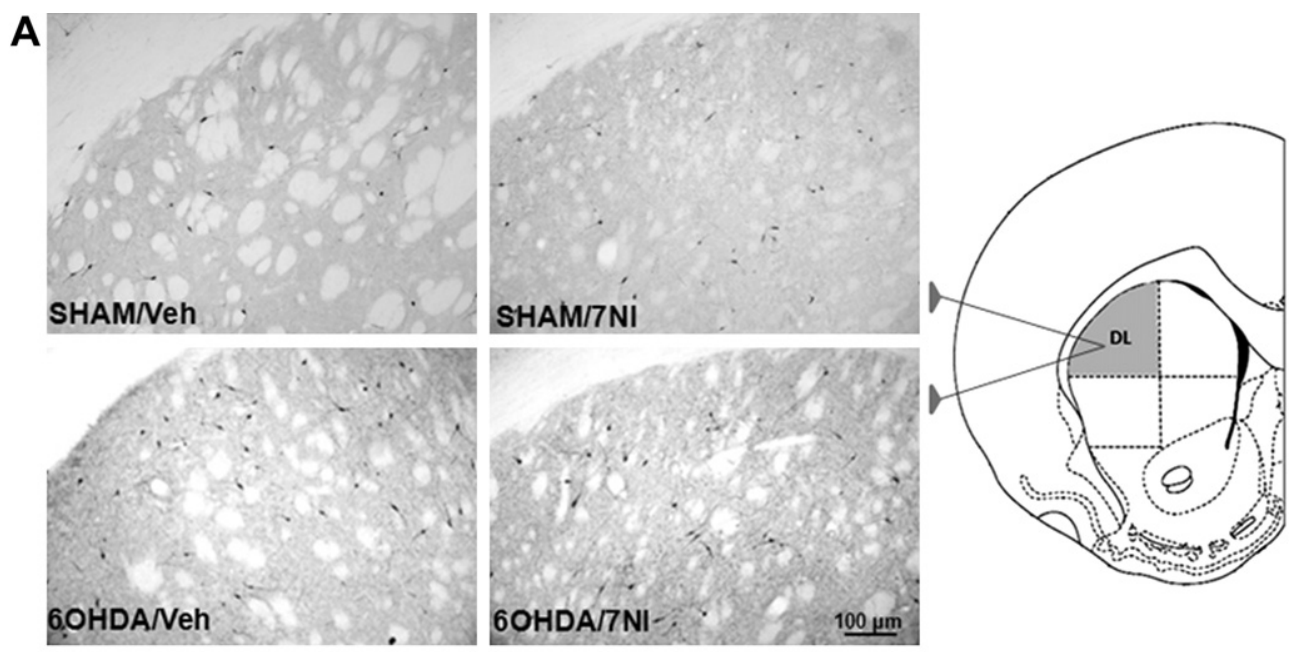

B

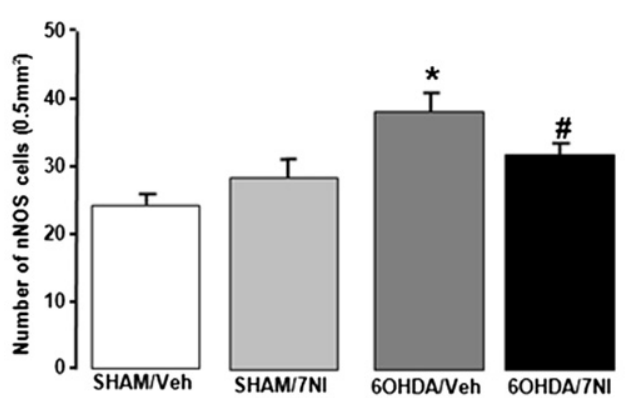

Fig. 2. Increase of striatal nNOS is reverted by 7-NI. (A) Photomicrographs show nNOS labeling in the dorsolateral striatum. An increase of nNOS ${ }^{+}$cells was observed in the 6-OHDA/ Veh group with respect to Sham animals (B) and was slightly lower in the 7-NI treatment (6-OHDA/7-NI). *P $<0.05$ 6-OHDA vs Sham groups, and \#P $<0.056-\mathrm{OHDA} / 7-\mathrm{NI}$ vs Sham/ Veh (ANOVA followed by the Duncan test).

\subsection{7-NI protects the nigrostriatal pathway in 6-OHDA-lesioned rats}

Histological analyses were carried out in the dorsolateral striatum region of interest, and in the SNpc area (in the ipsilateral side to the injection). Previously, an analysis of both sides was performed. In the dorsolateral striatum region, an interaction (ANOVA Repeated Measures, $F(3,16)=3.31, P=0.047)$, and effect in treatment factor was observed (ANOVA Repeated Measures, $F(3,16)=5.08, P=0.012$ ). Densitometry analysis revealed a significant reduction of $\mathrm{TH}^{+}$fibers in the lesioned-dorsolateral striatum of 6-OHDA rats. However, a significant effect was observed in the 6-OHDA/7-NI group (ANOVA, $F_{(3,19)}=23.42, P<0.001$ ) (Fig. 1, panel B.2). For lesion area, the ratio of the lesioned area (DA terminal loss) was calculated with ImageJ. The data were expressed in percentage of the total dorsolateral area. Sham/Veh: No lesion: 100\%, Sham/7-NI: No lesion: 100\%, 6-OHDA/ Veh: No lesion: $15.5 \%$; Lesion: $84.5 \%$ and 6-OHDA/7-NI: No lesion: $37.2 \%$; Lesion: $62.8 \%$. Besides, there was a significant negative correlation between the expression of striatal $\mathrm{TH}^{+}$fibers and rotational behavior $(r=-0.869, P<0.001)$. In the SNpc region (but not in $\mathrm{SN}_{\text {lat }}$ and $\mathrm{SN} \gamma$ ), a decrease in $\mathrm{TH}^{+}$neurons was seen in 6-OHDA/ Vehicle animals compared with Sham/vehicle and 6-OHDA/7-NI groups (ANOVA, $F_{(3,15)}=3.24, P<0.05$; Duncan, $P<0.05$ ) (Fig. 1, panel C.2). Moreover, in the other areas of the Substantia Nigra $\left(\mathrm{SN}_{\text {lat }}\right.$ and $\mathrm{SN} \gamma$ ) we did not find significant difference in $\mathrm{TH}^{+}$neurons in any groups (ANOVA, $F_{(3,15)}=3.24, P>0.05$ ) (Fig. 1, panel C.1). These changes were observed in the $\mathrm{SNpc}$, which projects toward the dorsolateral striatum.

\subsection{7-NI reduces nNOS striatal expression in 6-OHDA-lesioned rats}

Effect on treatment factor was observed (ANOVA Repeated Measures, $\left.F_{(3,15)}=3.52, P=0.041\right)$. The density of nNOS- immunoreactive positive neurons in the 6-OHDA/Vehicle group increased in the lesioned-dorsolateral striatum compared with Sham groups but it was partially reverted in 6-OHDA/7-NI group (ANOVA, $F_{(3,16)}=6.63, P<0.005$ ) (Fig. 2, panel B). The density of nNOS cells was negatively correlated with the density of $\mathrm{TH}^{+}$fibers (Fig. 5, panel A).

\subsection{7-NI reduces DARPP-32 phosphorylation in 6-OHDA-lesioned rats}

To accurately determine the increase in DARPP- $32^{+}$cell numbers in pathophysiological stages in postmortem brain, it is important to establish a positive control for the quantification in a non-involved brain area. In this case, in all the sections we analyzed the motor cortex, immediately above the striatum (Figs. 3-4, panel A) (Ouimet et al., 1984, 1998), also stained for control area for both total DARPP-32 and phosphoThr-34-DARPP32. Analysis with pospho-Thr34-DARPP-32 showed an interaction between both factors (ANOVA Repeated Measures, $F_{(3,16)}=5.15$, $P=0.011$ ). In lesioned-dorsolateral striatum, the number of pospho-Thr34-DARPP-32 cells was increased in the 6-OHDA/Vehicle group, which was significantly diminished in the 6-OHDA lesioned group treated with the nNOS inhibitor (ANOVA, $F_{(3,16)}=4.62$, $P<0.01$ ) (Fig. 4, panel D). An opposite effect was observed on the total DARPP- $32^{+}$cell number. Previously, an interaction between both factors was observed (ANOVA Repeated Measures, $\left.F_{(3,16)}=21.53, P<0.001\right)$, and an effect on the treatment factor (ANOVA Repeated Measures, $F_{(3,16)}=19.89, P<0.001$ ). In lesioneddorsolateral striatum, DARPP- $32^{+}$cells decreased in the 6-OHDA/ Vehicle group, whereas a significant increase was also found in the 6-OHDA/7-NI group (ANOVA, $F_{(3,17)}=27.4, P<0$.001; Duncan, $P<0.05$ ) (Fig. 3, panel D). Furthermore, a significant correlation was seen between the levels of phospho-Thr34-DARPP-32 and total 
A

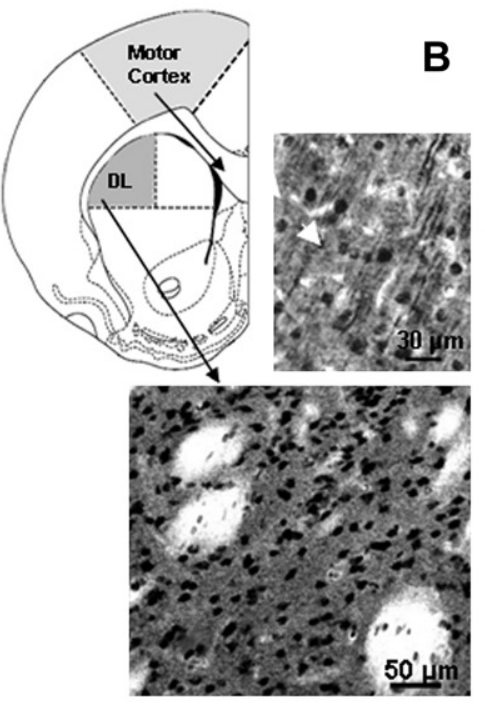

B

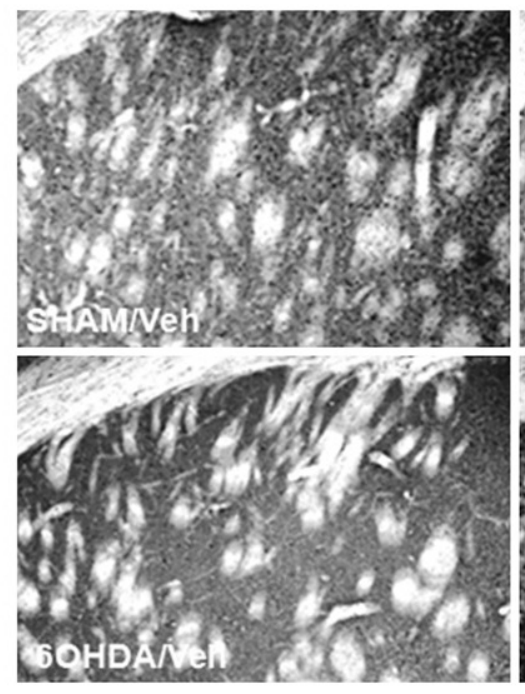

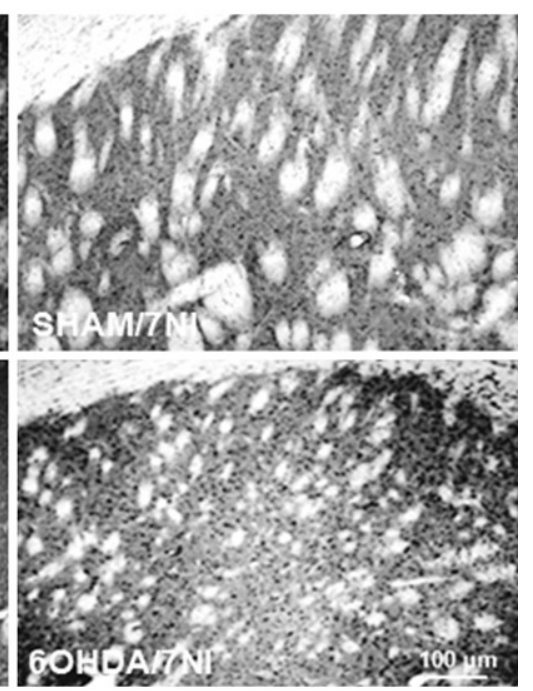
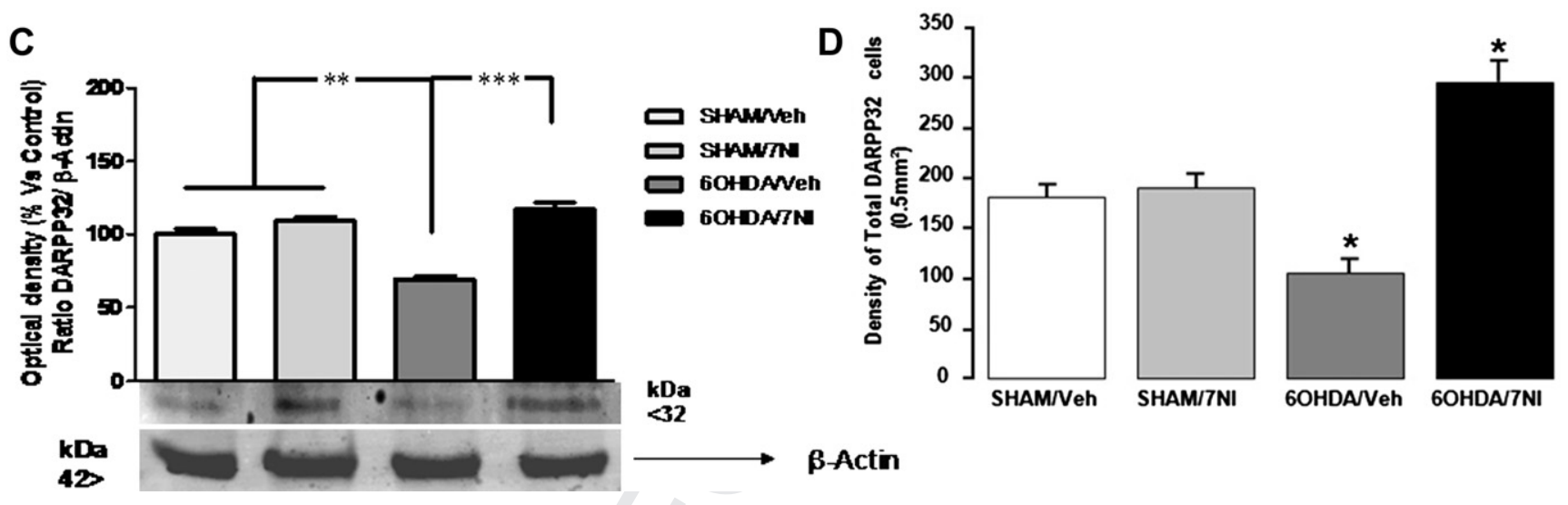

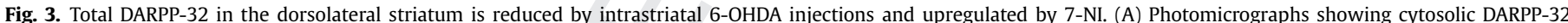

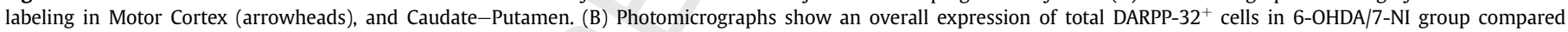

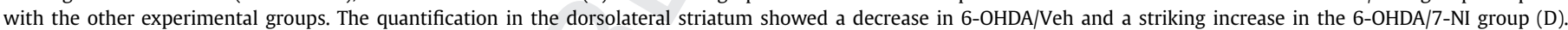

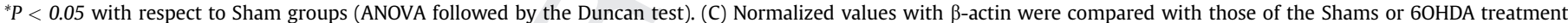

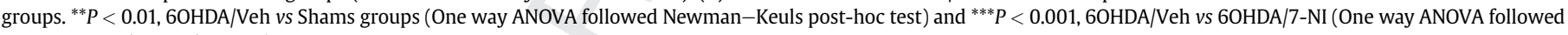
Newman-Keuls post-hoc test).

DARPP-32 (Fig. 5 panel B) which suggests consumption of the total DARPP-32 phosphorylated by NO mediated mechanisms. This means that PKG (via NO) phosphorylated total DARPP-32 and that the protein turns into its phosphorylated form (phospho-Thr34DARPP-32). In addition, a very significant positive correlation between nNOS labeling and the expression of pospho-Thr34DARPP-32 was observed ( $r=0.556, P=0.01$ ) (Fig. 5, panel C). Thus, these results demonstrate an association between the state of phosphorylation of DARPP-32 and nNOS cell number in the lesioned striatum.

\subsection{7-NI reduces values of phospho-DARPP-32 and increases total DARPP-32 in 6-OHDA-lesioned rats by western blot analysis}

Phospho-Thr43-DARPP-32 and total DARPP-32 immunoblots in the striatum were examined by Western blot analysis in control treated with 6-OHDA/Vehicle and treated with 6-OHDA+ 7-NI rats. As regards DARPP-32, total and phospho-DARPP-32 was detected in a band located at $\sim 32 \mathrm{kDa}$ (Figs. 3-4, panel C). In rats treated with 6-OHDA/7-NI, the total DARPP-32 protein increased significantly with respect to controls groups (ANOVA, post-hoc Newman-Keuls, $P<0.01$, Fig. 3, panel C). Similar results were obtained by immunohistochemistry. The opposite effect was observed in the
phospho-Thr34-DARPP-32, which increased in the 6-OHDA/Vehicle group with respect to controls animals (One Way ANOVA, post-hoc Newman-Keuls, $P<0.01$, Fig. 4, panel C). These data are in agreement with those obtained by immunohistochemistry, giving more consistency to the results.

\section{Discussion}

Based on quantitative immunohistochemical and behavioral analyses, the present study provides in vivo evidence for the upregulation of DARPP-32-signaling caused by a moderate DA depletion in the striatum, controlled by nNOS mediated mechanisms.

Our results show that a unilateral intrastriatal injection of 6OHDA in rats induces a slight loss of $\mathrm{TH}^{+}$fibers in the striatum and $\mathrm{TH}^{+}$cells in the $\mathrm{SNpc}$, associated with a low intensive rotation to apomorphine administration (Ungerstedt, 1971; Costall and Naylor, 1975; Herrera-Marschitz and Ungerstedt, 1984; Koob et al., 1984). Although drug-induced rotational behavior is widely used to evaluate the level of DA lesion, a more sensitive test (as we use in our model) should be used due to the sensitization effects of apomorphine. In our rats, this small DA depletion was reliably detected by rotational behavior and by a significant contralateral biased-swing 
A

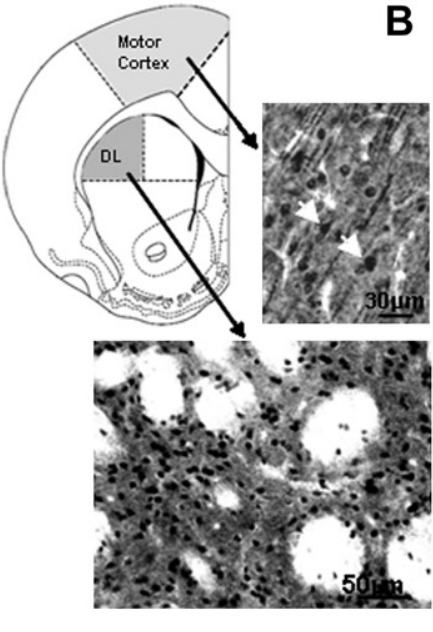

B

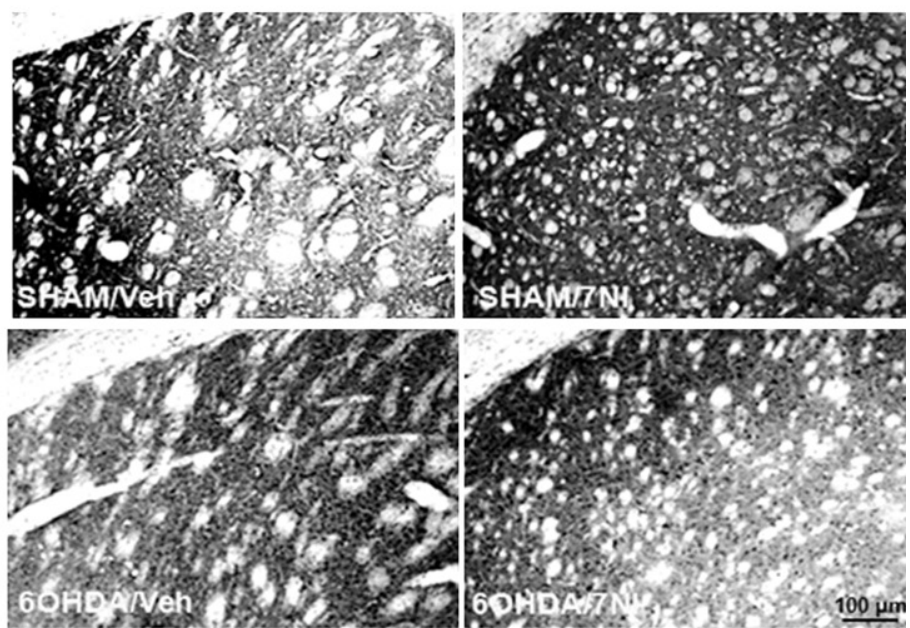

C
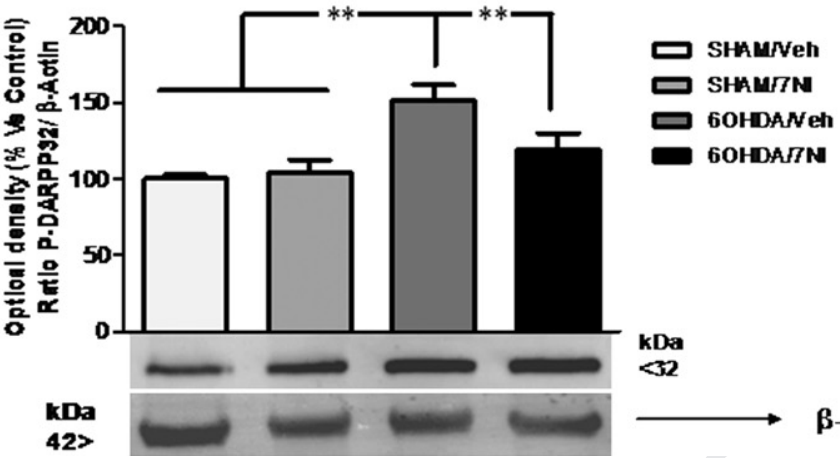

D

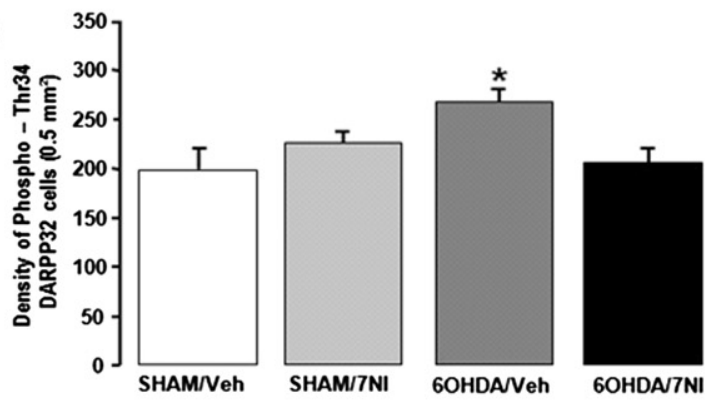

826

827

828

829

830

831

832

833

834

835

836

837

838

839

840

841

842

843

844

845

846

847

848

849

850

851

852

853

854

855

856 which is recognized as an important mediator of neuronal degeneration in the DA system (Smith and Cass, 2007). Subsequently, NOS 
Table 1

Quantification analysis in dorsolateral striatum region in the right and left hemisphere.

\begin{tabular}{|c|c|c|c|c|c|c|c|c|}
\hline & \multicolumn{2}{|l|}{$\mathrm{TH}^{\mathrm{a}}$} & \multicolumn{2}{|l|}{ nNOS } & \multicolumn{2}{|l|}{ Total DARPP-32 } & \multicolumn{2}{|c|}{ Thr34DARPP-32 } \\
\hline & $\mathrm{R}$ & $\mathrm{L}$ & $\mathrm{R}$ & $\mathrm{L}$ & $\mathrm{R}$ & $\mathrm{L}$ & $\mathrm{R}$ & $\mathrm{L}$ \\
\hline SHAM/Veh & $64.2 \pm 6.9$ & $60.3 \pm 4.6$ & $24.4 \pm 1.5$ & $27.5 \pm 2.2$ & $181.9 \pm 13.3$ & $192.3 \pm 13.4$ & $199.2 \pm 22.7$ & $214.1 \pm 12.6$ \\
\hline SHAM/7NI & $61.1 \pm 7.9$ & $62.1 \pm 5.3$ & $28.6 \pm 2.5$ & $28.4 \pm 2.0$ & $190.9 \pm 13.1$ & $182.2 \pm 4.9$ & $231.0 \pm 10.1$ & $203.0 \pm 20.5$ \\
\hline 60HDA/Veh & $12.1^{*} \pm 2.0$ & $60.1 \pm 5.4$ & $38.4^{*} \pm 2.8$ & $29.7 \pm 0.4$ & $105.9^{*} \pm 11.6$ & $177.4 \pm 6.0$ & $274.1^{*} \pm 13.8$ & $200.9 \pm 30.1$ \\
\hline $60 \mathrm{HDA} / 7 \mathrm{NI}$ & $26.8^{*} \pm 4.8$ & $58.0 \pm 5.1$ & $32.1 \# \pm 1.0$ & $29.6 \pm 4.5$ & $295.4^{*} \pm 20.8$ & $188.6 \pm 2.3$ & $207.1 \pm 12.6$ & $215.5 \pm 2.7$ \\
\hline
\end{tabular}

Other data are expressed as numbers of labeled cells $/ 0.5 \mathrm{~mm}^{2}$ and represented with mean \pm S.E.M. Further specifications as in results. $\mathrm{R}=$ right side and $\mathrm{L}=$ left side.

a $\mathrm{TH}$ was measured by optical density analysis.

NO has been shown to diffuse into medium spiny neurons and activate soluble guanylyl cyclases (sGC), resulting in the formation of transient increases in intracellular cGMP levels that can affect to medium spiny neuron (MSN) activity via activation of
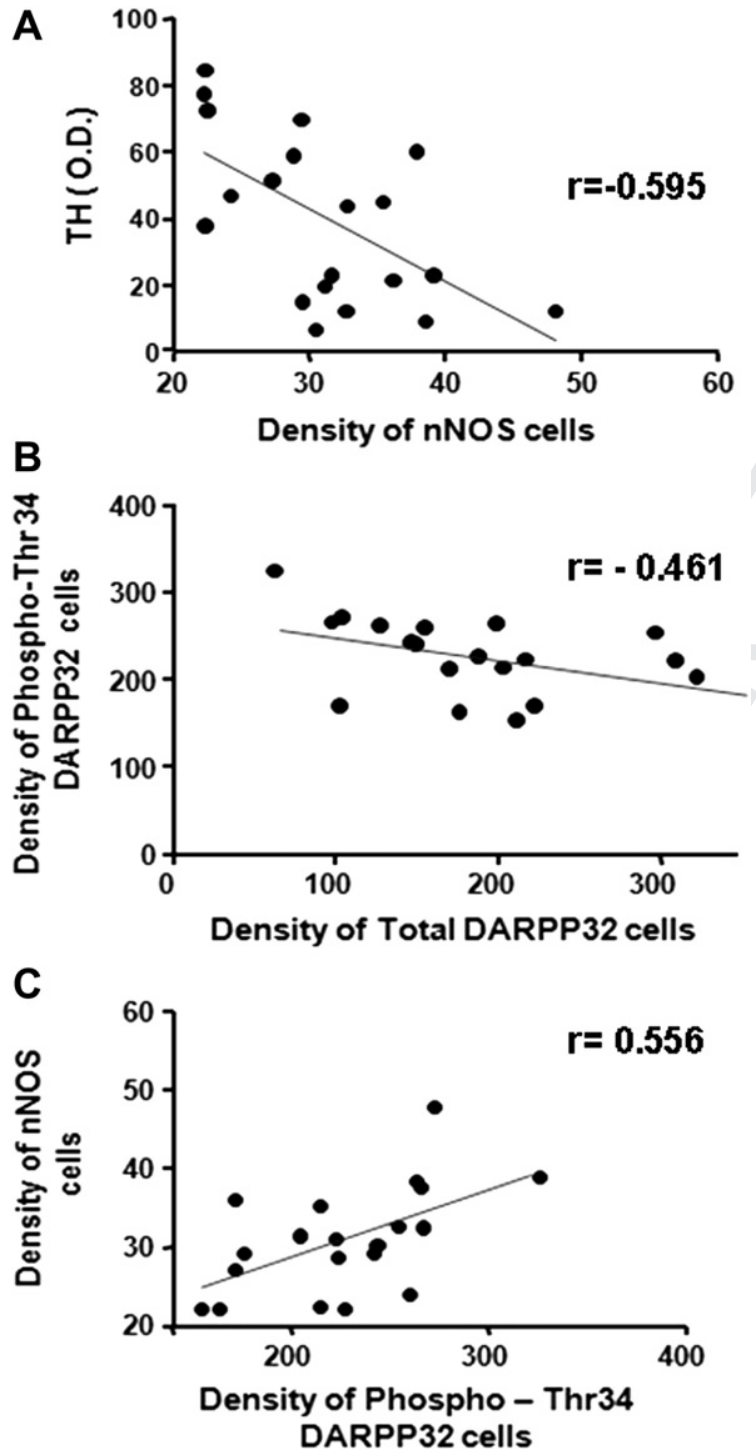

Fig. 5. Correlations of the changes in the dorsolateral striatum after 6-OHDA neurodegeneration. (A) Negative correlation between nNOS vs TH $(r=-0.595, P=0.0056$ Pearson $r$ correlation). An increased nNOS expression is associated with a decrease in TH positive neurons. (B) Negative correlation between Total DARPP-32 vs phosphoThr34-DARPP-32 ( $r=-0.4611, P=0.041$, Pearson $r$ correlation). An increase of total DARPP-32 expression is associated with a decrease in DARPP-32 phosphorylated positive neurons. (C) Positive correlation between Phospho-Thr34-DARPP-32 vs nNOS $(r=0.5562, P=0.011$, Pearson $r$ correlation). An increase of phospho-Thr34-DARPP-32 expression is associated with an increase in nNOS positive cells.
PKG and downstream targets (e.g., cyclic nucleotide gated channels) (West and Grace, 2004; West and Tseng, 2011), which then causes the increased phosphorylation of DARPP-32 in threonine residue 34 (Thr-34). This is because DARPP-32 at Thr34 is an excellent substrate for PKG as well as PKA and therefore the activated PKG induces the phosphorylation of DARPP-32 at Thr-34 (Hemmings et al., 1984; Tsou et al., 1993; Greengard et al., 1999).

Remarkably consistent outcomes have been reported in studies examining the impact of DA D1 and D2-like receptor agonists/ antagonists on striatal NOS activity and NO production via cGMP (Di Stefano et al., 2005; Sammut et al., 2006; Siuciak et al., 2006; Park and West, 2009; Hoque et al., 2010).

Together, these studies confirm that both D1 and D2-like receptor activation strongly regulates striatal nNOS activity, albeit in opposing manners (i.e., D1 receptor activation facilitates the activity, while, D2 receptor activation is inhibitory), and identify a critical role of nNOS-NO signaling in the generation of striatal cGMP.

Glutamate, by activating NMDA and AMPA receptors, stimulates the synthesis of NO in nNOS interneurons in the neostriatum (Tsou et al., 1993), and the synthesized NO regulates the function of MSNs (Calabresi et al., 2000). Glutamate also induces a rapid and transient increase in DARPP-32 Thr-34 phosphorylation. It is abolished by inhibitors of nNOS (as well 7-NI) and soluble guanylyl cyclase, indicating that glutamate activates nNOS in GABAergic interneurons, where nNOS is expressed in the neostriatum (Tsou et al., 1993).

Once phosphorylated, the DARPP-32 at Thr-34 inhibits protein phosphatase-1 (PP-1) activity (Svenningsson et al., 2004), acting as a cAMP-dependent kinase inhibitor (Svenningsson et al., 2004; Nishi et al., 2005). In fact, in the dorsolateral striatum, phosphorylation mechanisms play a physiological role in motor control, and the induction of both long-term depression (LTD) and long-term potentiation (LTP), two opposing forms of synaptic plasticity. Both forms of plasticity (LTP/LTD) are also critically linked to the activation of DA receptors, supporting the idea that in the striatum, a close interplay among DA receptors, DARPP-32 state phosphorylated/de-phosphorylated, and glutamatergic transmission might underlie the functional role of this structure in motor control and cognitive activities. (Calabresi et al., 2000, 2007).

In the context of experimental parkinsonism, our findings show that following dorsolateral striatal lesion with 6-OHDA, there is an increase in nNOS that may induce the phosphorylation of DARPP32 in Thr-34, with a concomitant decrease of total DARPP-32, suggesting that NO mediates a regulatory effect in experimental parkinsonism (Fig. 6). Importantly, DARPP-32, located in mediumsized spiny neurons in most cytosolic subcellular compartments including dendrites, axons and axon terminals, may provide the anatomical framework for the action of multiple outputs of the striatum regulated by NO in PD (Lindskog et al., 2002; Nairn et al., 2004). In this context, the regulation of DARPP-32 via nNOS may 

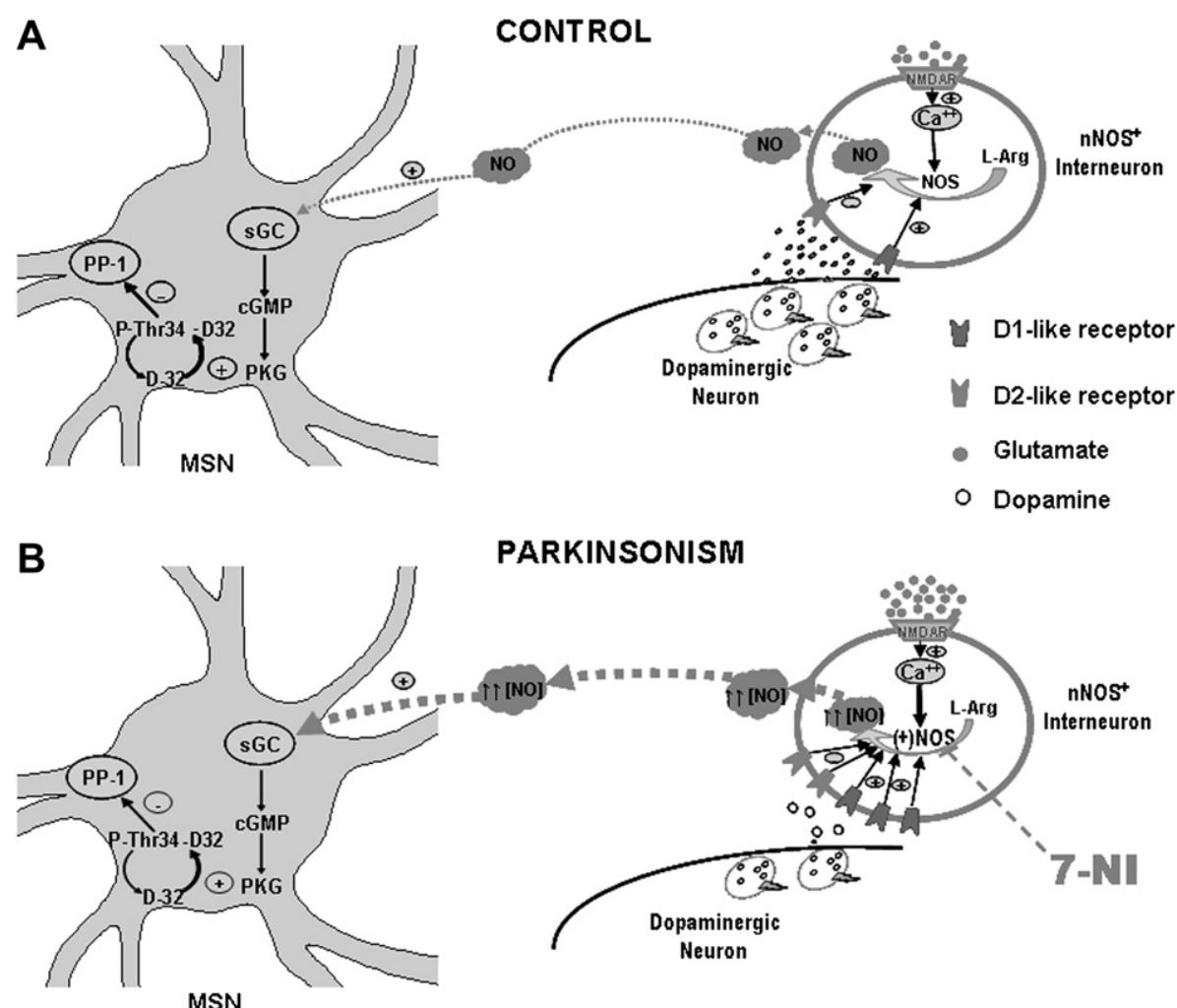

PARKINSONISM

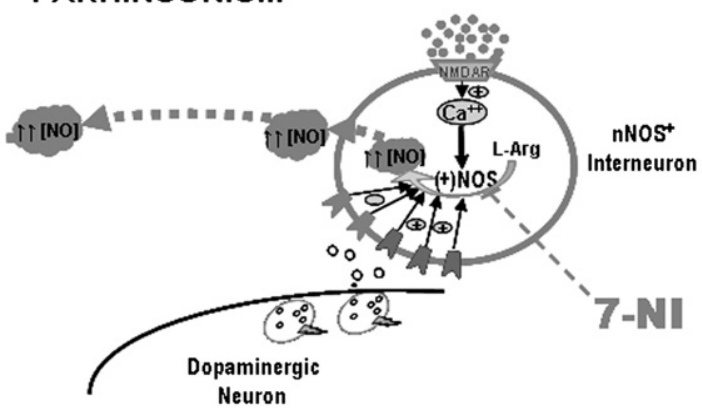

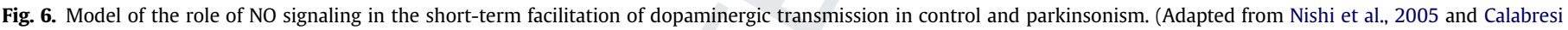

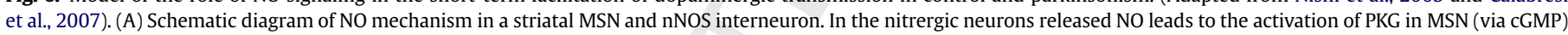

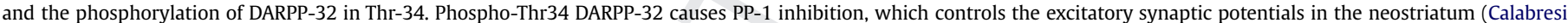

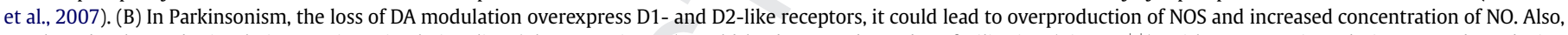

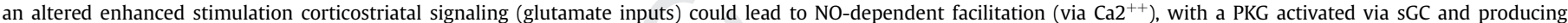

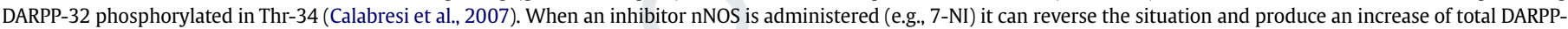
32 and a decrease of DARPP-32 phosphorylated. MSN: medium-sized spiny neuron. NMDAR: NMDA receptor.

represent a therapeutic target for controlling the disorganized activity of medium-sized spiny neurons in DA-depleted striatum in parkinsonism.

\section{Conclusions}

This study shows that a mild dorsolateral striatal 6-OHDA lesion, which provokes a significant increase of nNOS, is correlated with a positive balance of phospho-Thr34-DARPP-32 expression in the neostriatum. Importantly, treatment with 7-NI, apart from providing a neuroprotective effect, restores the striatal levels of phosphorylation DARPP-32 and increases the level of total DARPP32. These results throw light on the role of NO in regulating the activity of the striatum, suggesting that nNOS inhibitor may have a beneficial effect in restoring the neurotransmitter imbalance of the basal ganglia circuitry in parkinsonism.

\section{Acknowledgments}

This work was supported by grants from the Spanish Ministry of Science (SAF 2007-62262), FIS (PI/10/02827) and CIBERNED (Centro de Investigación Biomédica en Red sobre Enfermedades Neurodegenerativas). We would like thank all the personnel from SAI (Servicio de Apoyo a la Investigación), for the help provided at the University of Murcia, especially to Juan Miñarro. We thank Maria Angeles Carrillo, Valentina Annese and Victor Ortiz, for discussions concerning the experiments. The authors would also like to thank Mr. P. Thomas for comments and language suggestions on this manuscript. Finally, the authors declare that there is no conflict of interests in the present work.

\section{References}

Baluchnejadmojarad, T., Roghani, M., 2004. Evaluation of functional asymmetry in rats with dose-dependent lesions of dopaminergic nigrostriatal system using elevated body swing test. Physiol. Behav. 82 (2-3), 369-373.

Barcia, C., Sánchez Bahillo, A., Fernández-Villalba, E., Bautista, V., Poza Y Poza, M., Fernández-Barreiro, A., Hirsch, E.C., Herrero, M.T., 2004. Evidence of active microglia in substantia nigra pars compacta of parkinsonian monkeys 1 year after MPTP exposure. Glia 46 (4), 402-409.

Blandini, F., Armentero, M.T., Fancellu, R., Blaugrund, E., Nappi, G., 2004. Neuroprotective effect of rasagiline in a rodent model of Parkinson's disease. Exp. Neurol. 187 (2), 455-459.

Blandini, F., Levandis, G., Bazzini, E., Nappi, G., Armentero, M.T., 2007. Time-course of nigrostriatal damage, basal ganglia metabolic changes and behavioural alterations following intrastriatal injection of 6-hydroxydopamine in the rat: new clues from an old model. Eur. J. Neurosci. 25, 397-405.

Blum, D., Torch, S., Lambeng, N., Nissou, M., Benabid, A.L., Sadoul, R., Verna, J.M., 2001. Molecular pathways involved in the neurotoxicity of 6-OHDA, dopamine and MPTP: contribution to the apoptotic theory in Parkinson's disease. Prog. Neurobiol. 65, 135-172.

Borlongan, C.V., Sanberg, P.R., 1995. Elevated body swing test: a new behavioral parameter for rats with 6-hydroxydopamine-induced hemiparkinsonism. J. Neurosci. 15, 5372-5378.

Bredt, D.S., Snyder, S.H., 1990. Isolation of nitric oxide synthetase, a calmodulinrequiring enzyme. Proc. Nat. Acad. Sci. 87, 682-685.

Calabresi, P., Gubellini, P., Centonze, D., Picconi, B., Bernardi, G., Chergui, K., Svenningsson, P., Fienberg, A.A., Greengard, P., 2000. Dopamine and cAMPregulated phosphoprotein $32 \mathrm{kDa}$ controls both striatal long-term depression and long-term potentiation, opposing forms of synaptic plasticity. J. Neurosci. 20 (22), 8443-8451.

Calabresi, P., Picconi, B., Tozzi, A., Di Filippo, M., 2007. Dopamine-mediated regulation of corticostriatal synaptic plasticity. Trends Neurosci. 30 (5), 211-219. 
Costall, B., Naylor, R.J., 1975. A comparison of circling models for the detection of antiparkinson activity. Psychopharmacology (Berlin) 41, 57-64.

Costall, B., Marsden, C.D., Naylor, R.I., Pycock, C.J., 1976. The relationship between striatal and mesolimbic dopamine dysfunction and the nature of circling responses following 6-OHDA and electrolytic lesions of the ascending dopamine systems of rats brain. Brain Res. 118, 87-113.

Dawson, T.M., Snyder, S.H., 1994. Gases as biological messengers: nitric oxide and carbon monoxide in the brain. J. Neurosci. 14 (9), 5147-5159.

Debeir, T., Ginestet, L., Francois, C., Laurens, S., Martel, J.C., Chopin, P., Marien, M. Colpaert, F., Raisman-Vozari, R., 2005. Effect of intrastriatal 6-OHDA lesion on dopaminergic innervation of the rat cortex and globus pallidus. Exp. Neurol. 193, 444-454.

Denicola, A., Radi, R., 2005. Peroxynitrite and drug-dependent toxicity. Toxicology 208 (2), 273-288.

Di Matteo, V., Pierucci, M., Benigno, A., Crescimanno, G., Esposito, E., Di Giovanni, G., 2009. Involvement of nitric oxide in nigrostriatal dopaminergic system degeneration: a neurochemical study. Ann. NY Acad. Sci. 1155, 309-315.

Di Monte, D.A., Royland, J.E., Anderson, A., Castagnoli, K., Castagnoli Jr., N., Langston, J.W., 1997. Inhibition of monoamine oxidase contributes to the protective effect of 7-nitroindazole against MPTP neurotoxicity. J. Neurochem. 69 (4), 1771-1773.

Di Stefano, A., Sozio, P., Cacciatore, I., Cocco, A., Giorgioni, G., Costa, B., Montali, M., Lucacchini, A., Martini, C., Spoto, G., Di Pietrantonio, F., Di Matteo, E., Pinnen, F., 2005. Preparation and pharmacological characterization of trans-2-amino5(6)fluoro-6(5)-hydroxy-1-phenyl-2,3-dihydro-1H-indenes as D2-like dopamine receptor agonists. J. Med. Chem. 48, 2646-2654.

Echeverry, M.B., Guimarães, F.S., Del Bel, E.A., 2004. Acute and delayed restraint stress-induced changes in nitric oxide producing neurons in limbic regions. Neuroscience 125 (4), 981-993.

Ferrante, R.J., Hantraye, P., Brouillet, E., Beal, M.F., 1999. Increased nitrotyrosine immunoreactivity in Substantia Nigra neurons in MPTP treated baboons is blocked by inhibition of neuronal nitric oxide synthase. Brain Res. $823(1-2)$, $177-182$.

Gomes, M.Z., Raisman-Vozari, R., Del Bel, E.A., 2008. A nitric oxide synthase inhibitor decreases 6-hydroxydopamine effects on tyrosine hydroxylase and neuronal nitric oxide synthase in the rat nigrostriatal pathway. Brain Res. 1203, 160-169.

Gomez-Urquijo, S.M., Hökfelt, T., Ubink, R., Lubec, G., Herrera-Marschitz, M., 1999. Neurocircuitries of the basal ganglia studied in organotypic cultures: focus on tyrosine hydroxylase, nitric oxide synthase and neuropeptide immunocytochemistry. Neuroscience 94 (4), 1133-1151.

Greengard, P., Allen, P.B., Nairn, A.C., 1999. Beyond the dopamine receptor: the DARPP-32/protein phosphatase-1 cascade. Neuron 23 (3), 435-447.

Guevara, B.H., Cespedes, G.C., Cubeddu, L.X., 2002. Treatment with 7-nitroindazole enhances kainic acid induced cholinergic neurotoxicity in the rat striatum: a neuroprotective role for neuronal nitric oxide. Cell. Mol. Neurobiol. 22 (5-6), 827-834.

Hantraye, P., Brouillet, E., Ferrante, R., Palfi, S., Dolan, R., Matthews, R.T., Beal, M.F. 1996. Inhibition of neuronal nitric oxide synthase prevents MPTP-induced parkinsonism in baboons. Nat. Med. 2, 1017-1021.

Hemmings Jr., H.C., Williams, K.R., Konigsberg, W.H., Greengard, P., 1984. DARPP-32, a dopamine- and adenosine $3^{\prime}: 5^{\prime}$-monophosphate-regulated neuronal phosphoprotein. I. Amino acid sequence around the phosphorylated threonine. J. Biol. Chem. 259, 14486-14490.

Herrera-Marschitz, M., Ungerstedt, U., 1984. Evidence that striatal efferents relate to different dopamine receptors. Brain Res. 323 (2), 269-278.

Hoque, K.E., Indorkar, R.P., Sammut, S., West, A.R., 2010. Impact of dopamineglutamate interactions on striatal neuronal nitric oxide synthase activity. Psychopharmacology (Berlin) 207, 571-581.

Hornykiewicz, O., Kish, S.J., 1987. Biochemical pathophysiology of Parkinson's disease. Adv. Neurol. 45, 19-34.

Ignarro, L.J., 1990. Nitric oxide. A novel signal transduction mechanism for transcellular communication. Hypertension 16 (5), 477-483.

Iversen, S.D., Koob, G.F., 1977. Behavioral implications of dopaminergic neurons in the mesolimbic system. Adv. Biochem. Psychopharmacol. 16, 209-214.

Kirik, D., Rosenblad, C., Bjorklund, A., 1998. Characterization of behavioral and neurodegenerative changes following partial lesions of the nigrostriatal dopamine system induced by intrastriatal 6-hydroxydopamine in the rat. Exp. Neurol. 152, 259-277.

Koob, G.F., Simon, H., Herman, J.P., Le Moal, M., 1984. Neuroleptic-like disruption of the avoidance response requires destruction of both the mesolimbic and nigrostriatal dopamine systems. Brain Res. 303 (2), 319-329.

Lindskog, M., Svenningsson, P., Pozzi, L., Kim, Y., Fienberg, A.A., Bibb, J.A. Fredholm, B.B., Nairn, A.C., Greengard, P., Fisone, G., 2002. Involvement of DARPP32 phosphorylation in the stimulant action of caffeine. Nature $418,774-778$.

Marletta, M.A., 1994. Nitric oxide synthase: aspects concerning structure and catalysis. Cell 78 (6), 927-930.

Moncada, S., Palmer, R.M.J., Higgs, E.A., 1991. Nitric oxide: physiology, pathophysiology, and pharmacology. Pharmacol. Rev. 43, 109-142.

Murphy, S., Simmons, M.L., Agullo, L., Garcia, A., Feinstein, D.L., Galea, E., Reis, D.J., Minc-Golomb, D., Schwartz, J.P., 1993. Synthesis of nitric oxide in CNS glial cells. Trends Neurosci. 16 (8), 323-328.

Nairn, A.C., Svenningsson, P., Nishi, A., Fisone, G., Girault, J.A., Greengard, P., 2004 The role of DARPP-32 in the actions of drugs of abuse. Neuropharmacology 47 , $14-23$.
Nishi, A., Watanabe, Y., Higashi, H., Tanaka, M., Nairn, A.C., Greengard, P., 2005. Glutamate regulation of DARPP-32 phosphorylation in neostriatal neurons involves activation of multiple signaling cascades. PNAS 102 (4) 1199-1204.

Old, M.E., Jacques, D.B., Kopyov, O., 1999. Subthalamic responses to amphetamine and apomorphine in the behaving rat with a unilateral 6-OHDA lesion in the Substantia Nigra. Synapse 34, 228-240.

Ouimet, C.C., Miller, P.E., Hemmings Jr., H.C., Walaas, S.I., Greengard, P., 1984. DARPP32 , a dopamine- and adenosine $3^{\prime}: 5^{\prime}$-monophosphate-regulated phosphoprotein enriched in dopamine-innervated brain regions. III. Immunocytochemical localization. J. Neurosci. 4 (1), 111-124.

Ouimet, C.C., Langley-Gullion, K.C., Greengard, P., 1998. Quantitative immunocytochemistry of DARPP-32-expressing neurons in the rat caudatoputamen. Brain Res. 808, 8-12

Padovan-Neto, F.E., Echeverry, M.B., Tumas, V., Del-Bel, E.A., 2009. Nitric oxide synthase inhibition attenuates L-DOPA-induced dyskinesias in a rodent model of Parkinson's disease. Neuroscience 159 (3), 927-935.

Park, D.J., West, A.R., 2009. Regulation of striatal nitric oxide synthesis by local dopamine and glutamate interactions. J. Neurochem. 111, 1457-1465.

Paxinos, G., Watson, C., 1998. The Rat Brain in Stereotaxic Coordinates, fourth ed. Academic Press, New York

Pierucci, M., Galati, S., Valentino, M., Di Matteo, V., Benigno, A., Muscat, R. Pitruzzella, A., Di Giovanni, G., 2011. Nitric oxide modulation of the basal ganglia circuitry: therapeutic implication for Parkinson's disease and other motor disorders. CNS Neurol. Disord. Drug Targets 10, 777-791.

Przedborski, S., Levivier, M., Jiang, H., Ferreira, M., Jackson-Lewis, V., Donaldson, D. Togasaki, D.M., 1995. Dose-dependent lesions of the dopaminergic nigrostriata pathway induced by intrastriatal injection of 6-hydroxydopamine. Neuroscience 67, 631-647.

Sagi, Y., Mandel, S., Amit, T., Youdim, M.B., 2007. Activation of tyrosine kinase receptor signaling pathway by rasagiline facilitates neurorescue and restoration of nigrostriatal dopamine neurons in post-MPTP-induced parkinsonism. Neurobiol. Dis. 25 (1), 35-44.

Salum, C., Raisman-Vozari, R., Michel, P.P., Gomes, M.Z., Mitkovski, M., Ferrario, J.E. Ginestet, L., Del Bel, E.A., 2008. Modulation of dopamine uptake by nitric oxide in cultured mesencephalic neurons. Brain Res. 1198, 27-33.

Sammut, S., Dec, A., Mitchell, D., Linardakis, J., Ortiguela, M., West, A.R., 2006. Phasic dopaminergic transmission increases NO efflux in the rat dorsal striatum via a neuronal NOS and a dopamine $\mathrm{D}(1 / 5)$ receptor-dependent mechanism. Neuropsychopharmacology 31, 493-505.

Schwarting, R.K., Huston, J.P., 1996. The unilateral 6-hydroxydopamine lesion mode in behavioral brain research. Analysis of functional deficits, recovery and treatments. Prog. Neurobiol. 50, 275-331.

Siuciak, J.A., McCarthy, S.A., Chapin, D.S., Fujiwara, R.A., James, L.C., Williams, R.D. Stock, J.L., McNeish, J.D., Strick, C.A., Menniti, F.S., Schmidt, C.J., 2006. Genetic deletion of the striatum-enriched phosphodiesterase PDE10A: evidence for altered striatal function. Neuropharmacology 51, 374-385.

Smith, M.P., Cass, W.A., 2007. Oxidative stress and dopamine depletion in an intrastriatal 6-hydroxydopamine model of Parkinson's disease. Neuroscience 144 (3), 1057-1066

Southan, G.J., Szabó, C., 1996. Selective pharmacological inhibition of distinct nitric oxide synthase isoforms. Biochem. Pharmacol. 51 (4), 383-394.

Svenningsson, P., Nishi, A., Fisone, G., Girault, J.A., Nairn, A.C., Greengard, P., 2004 DARPP-32: an integrator of neurotransmission. Ann. Rev. Pharmacol. Toxicol. 44, 269-296.

Tsou, K., Snyder, G.L., Greengard, P., 1993. Nitric oxide/cGMP pathway stimulates phosphorylation of DARPP-32, a dopamine- and cAMP-regulated phosphoprotein, in the Substantia Nigra. Proc. Natl. Acad. Sci. 90, 3462-3465.

Ungerstedt, U., Arbuthnott, G.W., 1970. Quantitative recording of rotational behavior in rats after 6-hydroxy-dopamine lesions of the nigrostriatal dopamine system. Brain Res. 24 (3), 485-493.

Ungerstedt, U., 1971. Postsynaptic supersensitivity after 6-hydroxy-dopamine induced degeneration of the nigro-striatal dopamine system. Acta Physiol. Scand. Suppl. 367, 69-93.

Vincent, S.R., Kimura, H., 1992. Histochemical mapping of nitric oxide synthase in the rat brain. Neuroscience $46,755-784$

Volz, T.J., Schenk, J.O., 2004. L-arginine increases dopamine transporter activity in rat striatum via a nitric oxide synthase-dependent mechanism. Synapse 54 173-182.

Von Bohlen Und Halbach, 2004. Synucleins and their relationship to Parkinson's disease. Cell. Tissue Res. 318 (1), 163-174.

West, A.R., Grace, A.A., 2004. The nitric oxide-guanylyl cyclase signaling pathway modulates membrane activity states and electrophysiological properties of striatal medium spiny neurons recorded in vivo. J. Neurosci. 24 (8) 1924-1935.

West, A.R., Tseng, K.Y., 2011. Nitric oxide-soluble guanylyl cyclase-cyclic GMP signaling in the striatum: new targets for the treatment of Parkinson's disease? Front. Syst. Neurosci. 5, 55-59.

Wiechelman, K.J., Braund, R.D., Fitzpatrick, J.D., 1988. Investigation of the bicinchoninic acid protein assay: identification of the groups responsible for colour formation. Anal. Biochem. 175, 231-237.

Yuan, H., Sarre, S., Ebinger, G., Michotte, Y., 2005. Histological, behavioural and neurochemical evaluation of medial forebrain bundle and striatal 6-OHDA lesions as rat models of Parkinson's disease. J. Neurosci. Methods 144, 35-45 